\title{
Comparing the context specificity of extinction and latent inhibition
}

\author{
Ralph R. Miller ${ }^{1} \cdot$ Mario A. Laborda ${ }^{1,2} \cdot$ Cody W. Polack $^{1} \cdot$ Gonzalo Miguez $^{1,2}$
}

Published online: 23 June 2015

(C) Psychonomic Society, Inc. 2015

\begin{abstract}
Exposure to a cue alone either before (i.e., latent inhibition treatment) or after (i.e., extinction) the cue is paired with an unconditioned stimulus results in attenuated conditioned responding to the cue. Here we report two experiments in which potential parallels between the context specificity of the effects of extinction and latent inhibition treatments were directly compared in a lick suppression preparation with rats. The reversed ordering of conditioning and nonreinforcement in extinction and latent inhibition designs allowed us to examine the effect of training order on the context specificity of what is learned given phasic reinforcement and nonreinforcement of a target cue. Experiment 1 revealed that when conditioned-stimulus (CS) conditioning and CS nonreinforcement were administered in the same context, both extinction and latent inhibition treatments had reduced impacts on test performance, relative to excitatory conditioning when testing occurred outside the treatment context. Similarly, Experiment 2 showed that when conditioning was administered in one context and nonreinforcement was administered in a second context, the effects of both extinction and latent inhibition treatments were attenuated when testing occurred in a neutral context, relative to the context in which the CS was nonreinforced. The observed context specificity of extinction and latent inhibition treatments has been previously reported in both cases, but not in a single experiment under otherwise identical conditions. The results of the two experiments
\end{abstract}

Ralph R. Miller

rmiller@binghamton.edu

1 Department of Psychology, SUNY Binghamton, Binghamton, New York 13902-6000, USA

2 Universidad de Chile, Santiago, Chile convergently suggest that memory of nonreinforcement becomes context dependent after a cue is both reinforced and nonreinforced, independent of the order of training.

Keywords Latent inhibition $\cdot$ CS preexposure $\cdot$ Release from latent inhibition $\cdot$ Extinction $\cdot$ Renewal $\cdot$ Context shifts

Contiguous pairings between a conditioned stimulus (CS) and an unconditioned stimulus (US) endow the initially neutral CS with the potential to elicit a conditioned response (CR) that is usually characterized by the US (Pavlov, 1927). In a fear conditioning preparation, an initially neutral CS (e.g., a noise) that is paired with an aversive US (e.g., a mild footshock) comes to elicit conditioned suppression of some appetitively motivated baseline behavior, as if the subject anticipated an impending footshock. Central to the present experiments, conditioned responding is usually reduced by nonreinforced presentations of the CS, either after (i.e., extinction treatment; Pavlov, 1927) or before (i.e., latent inhibition treatment, which is also known as CS preexposure; Lubow \& Moore, 1959) excitatory conditioning (i.e., CS-US pairings).

The behavioral consequences of both extinction and latent inhibition treatments have been reported to be relatively specific to the contexts in which those treatments were administered. That is, responding is ordinarily greater outside the context of nonreinforcement (e.g., Harris, Jones, Bailey, \& Westbrook, 2000; Rescorla, 2008; Westbrook, Jones, Bailey, $\&$ Harris, 2000). Moreover, even when reports concerning the context specificity of extinction and latent inhibition effects appeared in the same publication, the observations typically have been made in separate experiments in which only extinction or only latent inhibition were examined, and the extinction and latent inhibition experiments have usually used distinctly different parameters. Thus, prior conflicting reports 
concerning the similarity of context specificity with respect to extinction and latent inhibition effects may actually reflect superficial differences in parameters used in or across experiments rather than actual differences in the context specificity of the response attenuating effects of extinction and latent inhibition treatments (e.g., Lovibond, Preston, \& Mackintosh, 1984; Maes, 2002). Critically, the present research examined the context specificity of extinction and latent inhibition effects within the same experiments using operationally matched parameters such as number of trials and trial spacing. This facilitated assessment of similarities and differences in context specificity of extinction and latent inhibition effects based uniquely on the information content of what is learned in the two types of nonreinforced treatments (i.e., differing only in terms of whether nonreinforcement follows or precedes reinforced training). We postpone until later in this article our discussion of why the similarities and differences in the context specificity of extinction and latent inhibition effects are of theoretical importance.

The operational similarities of extinction and latent inhibition treatments, as well as the cross-experiment reported similarities in the context specificity of expression of what is learned in these two situations, encouraged us to expect similarities in context specificity in the present experiments. However, the two nonreinforcement treatments occur on opposite sides of reinforced training with respect to time, which results in an extinction treatment constituting omission of a specific expected US in contrast with a latent inhibition treatment constituting nonreinforcement in the absence of expectation of any US. These two inherent differences (timing and information content of nonreinforcement) resulting from procedure suggest that what is learned may differ in the two situations. Consequently, one might expect differences in the context specificity of extinction and latent inhibition effects despite their both operationally consisting of nonreinforced presentations of the target CS.

In both Experiments 1 and 2, we employed $2 \times 2$ mixed designs, with different cues being used in the extinction and latent inhibition conditions being the within-subjects independent variable, and test context (that of nonreinforcement or a context neutral with respect to the test cue) being a betweensubjects independent variable. In both experiments, we omitted inclusion of a group that received no CS-alone presentations because we had previously demonstrated using similar parameters that the present conditioning treatment alone results in robust conditioned suppression in the form of a mean suppression latency of $2.0 \log \mathrm{s}$, as compared to unconditioned rats with a mean suppression latency of $0.9 \log \mathrm{s}$ (e.g., Wheeler, Chang, \& Miller, 2003, Exp. 2).

Given phasic reinforcement and nonreinforcement of a cue, there are many accounts of why a shift in context at the time of test to a context other than where nonreinforcement of the cue had occurred enhances conditioned responding. The two most widely cited accounts both were proposed by Bouton (e.g., 1993). The first posits that memory of nonreinforcement is context specific, so a shift from the context of nonreinforcement at the time of test attenuates retrieval of what was learned about nonreinforcement irrespective of the order of training (i.e., nonreinforcement before or after conditioning). Consequently, in the context shift condition deficient retrieval of memory of nonreinforcement should lead to more robust expression of excitatory conditioning (i.e., stronger behavioral control by the target cues) outside of the context of nonreinforcement (Group Different in the present experiments) than in the context of nonreinforcement (Group Same). Moreover, this enhancement of behavioral control should be equal for the extinguished and latently inhibited CSs. Bouton's second account posits that second-learned information about a cue is context specific, that is, retrieval of whichever memory about a cue was acquired second should be impaired when testing occurs outside of the context in which the second-learned relationship was acquired. Based on this mechanism, after a latent inhibition treatment, excitatory conditioning should only weakly transfer to a context in which the target cue has not previously been presented, resulting in attenuated behavioral control by the preexposed CS. In contrast, following an extinction treatment, nonreinforcement learning should only weakly transfer, resulting in relatively strong behavioral control by the extinguished CS. Note that both of these accounts attribute an occasion setting property to one of the treatment contexts, but they differ in the factor (i.e., site of nonreinforcement or site of second-learned information concerning the target cue) that determines which of the two treatment contexts will serve as the occasion setter. Although these two accounts of the context specificity of stimulus control following phasic reinforcement and nonreinforcement are by far the most widely cited, there are other accounts, some of which we will consider in the General Discussion.

\section{Experiment 1: Nonreinforcement and conditioning in the same context; test in treatment context or a context that is neutral with respect to the target cue}

In Experiment 1, we examined the sensitivity to test context of extinction and latent inhibition effects by administering nonreinforced exposure and conditioning of the target CSs in the same context, and then testing in the same context (Group Same) or a different context (Group Different). Conditioning without nonreinforced trials is known to transfer rather well to contexts different from that of conditioning (e.g., Bouton \& King, 1983; Nelson, 2002). Our question was whether the effects of an extinction treatment and a latent inhibition treatment (i.e., nonreinforced CS exposure) would transfer equally to a context different from that of treatment 
(i.e., where both conditioning and nonreinforced exposures to the CS had occurred) given identical operational treatments within the same experiment except for the temporal order of nonreinforcement of the target cues with respect to their reinforcement.

In Experiment 1 (see Table 1), using the conventional nomenclature of context shift effects - in which the first of three letters specifies the context of Phase 1 treatment, the second letter specifies the context of Phase 2 treatment, and the third letter specifies the test context-we compared an $\mathrm{AAB}$ context shift condition (Group Different) with an AAA control condition (Group Same) for both extinction and latent inhibition conditions. All rats received preexposure to CS Y in Context $\mathrm{B}$ prior to independent pairings of CS $\mathrm{Y}$ with a footshock US in Context B and CS X with the same US in Context A, followed by the extinction of CS X in Context A. At test, half of the rats were tested for conditioned suppression to $\mathrm{X}$ and $\mathrm{Y}$ in the contexts in which each of these cues were nonreinforced (here reinforced; Group Same: Y in Context B and X in Context A). The other half of the rats were tested for suppression to $\mathrm{X}$ and $\mathrm{Y}$ in contexts different from those used for the treatments of the cues being tested (Group Different: $\mathrm{Y}$ in Context $\mathrm{A}$ and $\mathrm{X}$ in Context $\mathrm{B}$ ). This procedure allowed us to directly compare conditioned suppression after an extinction treatment in an $\mathrm{AAB}$ renewal design (i.e., $\mathrm{AAB}$ vs. AAA) with suppression in the analogous design for latent inhibition (i.e., BBA vs. $\mathrm{BBB}$, in the notation of Table 1). The context specificity of the expression of knowledge concerning nonreinforcement should have been equal for the extinction and latent inhibition treatments. However, if what was learned second was context specific, testing outside the context in which the target cue was nonreinforced should have generated greater recovery in the extinction condition than in the latent inhibition condition. Such an effect would take the form of an interaction between the cue (X vs. Y) and the test context (Same vs. Different).

\section{Method}

\section{Subjects}

The subjects were 24 male (224-315 g) and 24 female (173$218 \mathrm{~g}$ ), young adult, experimentally naive, Sprague-Dawley descended rats obtained from our own breeding colony. The subjects were randomly assigned to one of two groups (Groups Same and Different, $n \mathrm{~s}=24$ ), counterbalanced within groups for sex. The animals were individually housed in standard hanging stainless steel wire mesh cages in a vivarium maintained on a 16:8-h light:dark cycle. Experimental manipulations occurred near the middle portion of the light phase. The animals received free access to Purina Lab Chow, whereas water availability was limited to $30 \mathrm{~min}$ per day following a progressive deprivation schedule initiated one week prior to the start of the study. From the time of weaning until the start of the study, all animals were handled for $30 \mathrm{~s}$, three times per week.

\section{Apparatus}

Twenty-four experimental chambers of two different types were used to create two distinct contexts. Chamber V (12 instances) was a $27-\mathrm{cm}$-long box in a truncated-V shape $(29.5 \mathrm{~cm}$ in height, $21.5 \mathrm{~cm}$ wide at top, and $5.5 \mathrm{~cm}$ wide at bottom). The floor was comprised of two 27-cm-long, 2-cmwide stainless plates, with a $1.5-\mathrm{cm}$ gap between the two plates. A constant-current footshock, produced by a high voltage $\mathrm{AC}$ circuit in series with a $1.0-\mathrm{M} \Omega$ resistor could be delivered through the metal walls and floor of the chamber. The ceiling was clear Plexiglas, the front and back walls were black Plexiglas, and the sidewalls were stainless steel. Each instance of Chamber V was housed in a separate sound- and light-attenuating environmental isolation chest. The chamber was illuminated by a 7-W (nominal at $120 \mathrm{VAC}$, but driven at $50 \mathrm{VAC}$ ) light bulb, which was mounted on the inside wall of the environmental enclosure, approximately $30 \mathrm{~cm}$ from the center of the experimental chamber. The light entered the chamber primarily by reflection from the ceiling of the environmental chest. Each Chamber V could be equipped with a water-filled lick tube that extended $1 \mathrm{~cm}$ into a cylindrical niche, which was $4.5 \mathrm{~cm}$ in diameter, left-right centered, with its bottom $1.75 \mathrm{~cm}$ above the floor of the apparatus and $5.0 \mathrm{~cm}$ deep. A photobeam detector located $1 \mathrm{~cm}$ in front of the lick tube was broken whenever a subject licked the tube.

Chamber $\mathrm{R}$ (12 instances) was rectangular, measuring 24.0 $\times 9.0 \times 12.5 \mathrm{~cm}(1 \times \mathrm{w} \times \mathrm{h})$. The walls and ceiling of Chamber $\mathrm{R}$ were clear Plexiglas, and the floor was composed of stainless steel rods measuring $0.5-\mathrm{cm}$ diameter, spaced $1.3 \mathrm{~cm}$ apart (center to center), with the rods being connected by NE-2 bulbs that allowed the delivery of a constant-current footshock. Each instance of Chamber R was housed in a separate light- and sound-attenuating environmental isolation chamber. Each chamber was dimly illuminated by a $2-\mathrm{W}$ (nominal at $120 \mathrm{VAC}$, but driven at $50 \mathrm{VAC}$ ) incandescent house light mounted on an inside wall of the environmental chest located approximately $30 \mathrm{~cm}$ from the animal enclosure. Each Chamber R could be equipped with a water-filled lick tube identical to that in Chamber V.

Two $45-\Omega$ speakers on the inside walls of each isolation chest could deliver a click train $(6 \mathrm{~Hz}, 6 \mathrm{~dB}$ above background) and a complex tone (450 and $550 \mathrm{~Hz}$ simultaneously, $6 \mathrm{~dB}$ above background). Ventilation fans in each isolation chest provided a constant $76 \mathrm{~dB}$ of background noise. All auditory cues were measured on the $\mathrm{C}$-scale. The light intensities inside Chambers V and $\mathrm{R}$ were approximately equal due to the difference in opaqueness of the walls. 
Table 1 Design summary of Experiment 1

\begin{tabular}{|c|c|c|c|c|c|}
\hline Groups & CS Preexposure & Conditioning & CS Extinction & Context Extinction & Test \\
\hline \multirow[t]{2}{*}{ Same } & $32 \mathrm{Y}-(\mathrm{B})$ & $4 \mathrm{X}+(\mathrm{A})$ & $32 \mathrm{X}-(\mathrm{A})$ & $480 \min (\mathrm{A})$ & $\mathrm{X}(\mathrm{A})$ \\
\hline & & $4 \mathrm{Y}+(\mathrm{B})$ & & $480 \min (B)$ & $\mathrm{Y}(\mathrm{B})$ \\
\hline \multirow[t]{2}{*}{ Different } & $32 \mathrm{Y}-(\mathrm{B})$ & $4 \mathrm{X}+(\mathrm{A})$ & $32 \mathrm{X}-(\mathrm{A})$ & & $\mathrm{X}(\mathrm{B})$ \\
\hline & & $4 \mathrm{Y}+(\mathrm{B})$ & & & $\mathrm{Y}(\mathrm{A})$ \\
\hline
\end{tabular}

"Same" and "Different" refer to whether testing occurred in the context used for both the nonreinforcement treatment and excitatory conditioning (Same) or in a different context. $\mathrm{X}$ and $\mathrm{Y}$ were a click train and a tone, counterbalanced. "+" denotes reinforcement with a mild footshock; "-" denotes no reinforcement. Letters in parentheses indicate contexts, and Contexts A and B were counterbalanced. Numbers preceding the letters indicate the total number of trials in that phase

A 30 -s click train and a 30 -s complex tone served as CS X (target cue to be extinguished) and CS Y (target cue to be preexposed), counterbalanced within groups, and a $0.7-\mathrm{mA}, 0.5$-s footshock served as the US. The physical identities of Contexts A and B were counterbalanced between Chambers R and V within groups. Importantly, the design used in this experiment (as well as the subsequent one) assured that the test contexts were matched with respect to total exposure as well as reinforced and nonreinforced events that occurred in them except for which specific CS (extinguished or preexposed cue) had been nonreinforced in it.

\section{Procedure}

Acclimation On Day 1, all subjects were acclimated to Contexts $\mathrm{A}$ and $\mathrm{B}$ for 30 min each with the order of sessions counterbalanced within groups. The time between sessions was approximately $200 \mathrm{~min}$. In these sessions, subjects had free access to water-filled lick tubes and no nominal stimuli were programmed to occur.

CS preexposure On Days 2 and 3, all subjects received a daily 60-min session in Context B with no lick tube present. Subjects in both groups received 16 daily nonreinforced presentations of $\mathrm{Y}$ with a mean intertrial interval (ITI) of $3.75 \mathrm{~min}$, from CS onset to CS onset.

CS conditioning On Days 4 and 5, all subjects received two daily 60-min sessions, one consisting of two presentations of CS X coterminating with the US in Context A with 30-min ITIs (from CS onset to CS onset), and the other consisting of two presentations of Y coterminating with the US in Context B with the same ITI. The order of these sessions was counterbalanced within groups

CS extinction On Days 6 and 7, all subjects received a daily 60 -min session in Context A with no lick tube present. The subjects in both groups received 16 daily nonreinforced presentations of $\mathrm{X}$ with a mean ITI of $3.75 \mathrm{~min}$, from CS onset to CS onset.

Reacclimation On Days $8-11$, all subjects were reacclimated to Contexts A and B during daily 120-min sessions, with the order of sessions counterbalanced within groups. The time between sessions was approximately $240 \mathrm{~min}$ and no nominal stimulus was programmed to occur during this phase. On Days 10 and 11, but not on Days 8 and 9, all subjects had free access to water-filled lick tubes. Sessions in this phase had two aims: (a) to provide similar baseline drinking behavior in both contexts across both groups, and (b) to increase sensitivity to context shift effects in extinction and latent inhibition designs when reinforced and nonreinforced trials occurred in the same context. Prolonged exposure to the test context (i.e., context extinction) has been shown to enhance responding following extinction (e.g., Laborda, Witnauer, \& Miller, 2011) and latent inhibition (e.g., Escobar, Arcediano, \& Miller, 2002) paradigms in which reinforced and nonreinforced trials have been presented in the same context, as in the present design. Without the additional context extinction, recovery from the effects of extinction and latent inhibition treatments is relatively hard to detect when both acquisition and nonreinforcement are given in the same context. The extensive amount of reacclimation was necessitated by the fact that during conditioning, footshocks had been administered in Contexts A and B.

Testing All subjects were tested once daily on two consecutive days (Days 12-13). During test sessions, the subjects had free access to the water-filled tubes. All subjects were tested for conditioned lick suppression to $\mathrm{X}$ and $\mathrm{Y}$ on separate days, with the order of testing being counterbalanced within groups. The subjects in Group Same were tested in the contexts in which each CS was trained (i.e., $\mathrm{X}$ in Context $\mathrm{A}$ and $\mathrm{Y}$ in Context $\mathrm{B}$ ), whereas the subjects in Group Different were tested in contexts different than those in which each CS was trained (i.e., $\mathrm{X}$ in Context $\mathrm{B}$ and $\mathrm{Y}$ in 
Context A). On both tests, upon placement in the test chamber, the time spent drinking by each subject was recorded. Immediately after the completion of an initial 5 cumulative seconds of licking in the absence of any nominal stimulus, subjects were presented with the target cue. Thus, all subjects were drinking at the time of CS onset. The time to complete an additional 5 cumulative seconds of licking in the presence of the target cue was recorded and interpreted as reflecting the subjects' conditioned fear of the CS. The test session was $11 \mathrm{~min}$ in duration, with a ceiling score of $10 \mathrm{~min}$ on the time to complete 5 cumulative seconds of drinking in the presence of the target cue. All test scores were converted to $\log _{10}$ in order to better approximate the within-group normal distributions assumed by parametric statistical tests. Following the convention of our laboratory, all animals that took more than $60 \mathrm{~s}$ to complete their first 5 cumulative seconds of licking (i.e., prior to CS onset) during the test session were scheduled to be eliminated from the study because such long latencies were considered indicative of unusually great fear of the test context. In practice, one animal from Group Same was eliminated from the subsequent statistical analysis.

\section{Results}

The results of Experiment 1 are depicted in Fig. 1. When subjects were tested outside the context of treatment for the target cues (Group Different), they exhibited strong conditioned suppression to cues that received an extinction treat-

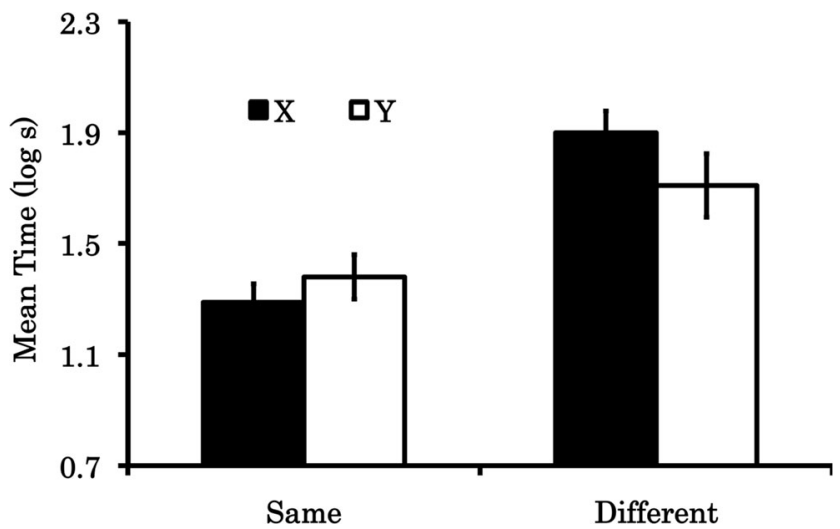

Fig. 1 Results of Experiment 1: Mean $\log _{10}$ times to complete 5 cumulative seconds of licking in the presence of the target CSs $\mathrm{X}$ and $\mathrm{Y} . \mathrm{X}=$ target cue that received extinction treatment; $\mathrm{Y}=$ target cue that received CS-preexposure treatment; Same = group that was tested for responding to $\mathrm{X}$ and $\mathrm{Y}$ in the context in which each of the cues was trained (i.e., $\mathrm{X}$ in Context $\mathrm{A}$ and $\mathrm{Y}$ in Context $\mathrm{B}$ ); Different = group that was tested for responding to $\mathrm{X}$ and $\mathrm{Y}$ outside the context in which each of the cues was trained (i.e., $\mathrm{X}$ in Context $\mathrm{B}$ and $\mathrm{Y}$ in Context $\mathrm{A}$ ). Brackets represent the standard errors of the means. Higher scores indicate more conditioned fear, and $0.7 \log \mathrm{s}$ was the lowest possible score. See the text and Table 1 for further details ment $(\mathrm{X})$ or a preexposure treatment $(\mathrm{Y})$, as compared with the behavior of subjects when testing occurred in the context of treatment for the test cue (Group Same). More specifically, testing an extinguished cue in a neutral (with respect to that cue) but familiar context produced more conditioned suppression than did testing the same cue in the context in which the conditioning and extinction treatments had taken place. Likewise, testing a preexposed cue in a neutral (with respect to that cue) but familiar context produced more conditioned suppression than did testing the same cue in the context in which preexposure and conditioning had occurred. Additionally, the amounts of conditioned suppression to $\mathrm{X}$ and $\mathrm{Y}$ were equivalent in Group Same and were also equivalent in Group Different. The following statistical analysis supported these conclusions.

A 2 (Context of Testing: Same vs. Different) $\times 2$ (Cue: X vs. Y) $\times 2$ (Order of Tests: $\mathrm{X}$ first vs. Y first) analysis of variance (ANOVA) applied to the log pre-CS latencies on the test days detected no significant main effect or interaction (smallest $p=.17$ ), indicating that the experimental groups did not appreciably differ in their baseline drinking. The pre-CS means were $1.16 \log$ s (Group Same X), 1.20 $\log \mathrm{s}$ (Group Same Y), $1.23 \log \mathrm{s}$ (Group Different X), and $1.24 \log \mathrm{s}$ (Group Different Y). The same analysis on latencies to complete 5 cumulative seconds of drinking in the presence of the CS detected a main effect of the context of testing, $F(1,86)=28.81, p<.01, M S E=0.19, \eta_{\mathrm{p}}{ }^{2}=0.25$ $(95 \% \mathrm{CIs}=.11, .39)$. This indicates that, overall, when subjects were tested in a context different from that of the nonreinforcement treatment, they displayed strong conditioned suppression relative to subjects tested in the context of treatment. All other main effects and interactions were nonsignificant, smallest $p=.12$.

Planned comparisons were performed to evaluate the differences between responding to $\mathrm{X}$ and $\mathrm{Y}$ within each group. A nonsignificant difference in responding to $\mathrm{X}$ and $\mathrm{Y}$ in Group Same, $F(1,86)=0.48, p=.49$, and a nonsignificant difference in responding to the same cues in Group Different, $F(1,86)=$ $2.37, p=.13$, indicated that suppression to $\mathrm{X}$ and $\mathrm{Y}$ did not differ appreciably in either group. The similarity of the means between responding to $\mathrm{X}$ and $\mathrm{Y}$ in Group Same and between responding to $\mathrm{X}$ and $\mathrm{Y}$ in Group Different was confirmed by Bayesian analyses (Rouder, Speckman, Sun, Morey, \& Iverson, 2009), with odds of 21.36 in favor of the null hypothesis for the comparison in Group Same, and odds of 5.21 in favor of the null hypothesis for the comparison in Group Different.

If one assumes that each of the excitatory conditioning and nonreinforced exposures to a target cue in the present situation produced its own memory, independent of the order of training, and that as Bouton (1993) suggested, twoand only two - (potentially additive) factors contribute to the context specificity of a memory (i.e., the memory is a 
second-learned contingency concerning the cue, ${ }^{1}$ and the memory is one of nonreinforcement), the present observations provide a means of dissociating the influences of these two factors. With these assumptions, the context specificity of a latent inhibition effect reflects only the context specificity of the memory of nonreinforcement, and the context specificity of an extinction effect reflects the sum of the context specificity of a memory of nonreinforcement and the context specificity of nonreinforcement being the second thing learned. Applying this reasoning to the results of Experiment 1, the observed context specificity of the latent inhibition effect with CS Y (the preexposed cue) evidences significant context specificity of the latent inhibition effect arising from $\mathrm{Y}$ being nonreinforced. Moreover, the absence of greater context specificity of extinction effects with CS X (the extinguished cue) suggests that nonreinforcement of $\mathrm{X}$ acquired no additional context specificity due to its being the second-learned relationship concerning $X$, over the context specificity of the memory of X-alone trials resulting from $\mathrm{X}$ having been nonreinforced. Alternatively stated, Experiment 1 provided evidence that memory of nonreinforcement is context specific, but no evidence that the second-learned memory of nonreinforcement is any more context specific than occurs when the corresponding memory is not learned second.

The above reasoning ignores the possibility that the excitatory conditioning of CS Y was to some degree context specific because it was the second thing learned about $\mathrm{Y}$. However, to the extent that this process reduced suppression to CS Y in Condition Different, it could only have masked an even greater context specificity of nonreinforcement of CS Y than was observed. The context specificity of the effect of excitatory conditioning of CS Y would have favored less conditioned suppression to CS Y in Context Different than in Context Same, potentially contributing to less of a context shift effect with CS Y than with CS X, which was in fact not observed. Alternatively stated, any context specificity of the memory of excitatory training of CS Y would have contributed to a difference in the context specificities of CS X and CS Y in the opposite direction from the one needed to explain why suppression to CS X was not greater than that to CS Y. Of course, the "if" opening the preceding paragraph is critical; a number of assumptions were made there, on which the subsequent reasoning depends. We delay until the General Discussion an alternative account of the results of Experiment 1 that will be based on Wagner's (1981) SOP model.

\footnotetext{
${ }^{1}$ Here we refer to the view that second-learned information about a cue is context dependent. Nelson (2009) has demonstrated that this position for two-phase training situations is a special case of a more general position in which anything learned about a cue that is inconsistent with prior learning about that cue (i.e., second-learned, third-learned, etc., information) is context specific.
}

\section{Experiment 2: Nonreinforcement and conditioning in different contexts: test in nonreinforcement context or a context that is neutral with respect to the target cue}

Experiment 1 suggested that given phasic reinforcement and nonreinforcement of a CS in the same context, the expression of memory of CS nonreinforcement is specific to the treatment context independent of whether reinforcement or nonreinforcement was experienced first. A potential complication for interpreting the results of Experiment 1 is that by testing inside of the context of the nonreinforcement treatment (Group Same), we were also testing inside the context in which excitatory conditioning of the CS had occurred. Thus, the context specificity of the expression of learning about noneinforcement was confounded by the potential context specificity of the expression of excitatory learning. This raises the question of whether the context specificity of the expression of memories because they were acquired second that we did not observe in Experiment 1 might have been observed with a design in which nonreinforced exposure to the target CS occurred in a context different from that of conditioning, and in which testing occurred in the nonreinforcement context or a context that was neutral with respect to the target cue. Experiment 2 was designed to answer this question.

In Experiment 2 (see Table 2), all rats received preexposure to $\mathrm{CS} Y$ in Context $\mathrm{C}$ prior to independent pairings of CS $\mathrm{X}$ and CS Y with a footshock US in Context A, followed by extinction of CS X in Context B. At test, half of the rats were tested for conditioned suppression to $\mathrm{X}$ and $\mathrm{Y}$ in the contexts in which each of these cues were nonreinforced (Group Same: $\mathrm{X}$ in Context $\mathrm{B}$ and $\mathrm{Y}$ in Context $\mathrm{C}$ ), and the other half of the rats were tested for suppression to $\mathrm{X}$ and $\mathrm{Y}$ in contexts different from those used for the nonreinforced treatment of the cue being tested (Group Different: $\mathrm{X}$ in Context $\mathrm{C}$ and $\mathrm{Y}$ in Context B). As a result of being tested outside the context of nonreinforcement for that particular CS, Group Different was expected to exhibit a release from latent inhibition (CS $\mathrm{Y})$ and recovery from extinction (CS X). This procedure allowed us to directly compare conditioned suppression to CS X after an extinction treatment, in what is conventionally referred to as an $\mathrm{ABC}$ renewal design (i.e., $\mathrm{ABC}$ vs. $\mathrm{ABB}$ ) with suppression in the analogous design for latent inhibition (i.e., $\mathrm{CAB}$ vs. $\mathrm{CAC}$, in the notation of Table 2). Again, the context specificities of expressions of knowledge concerning nonreinforcement per se should have been equal for the extinction and latent inhibition treatments. However, if what was learned second about the target CS was also context specific, testing in a "neutral" context (i.e., neutral with respect to the cue being tested) relative to the context of nonreinforcement should have generated greater recovery in the extinction condition than would be shown in the latent inhibition condition. This is because in the extinction condition, the increased 
Table 2 Design summary of Experiment 2

\begin{tabular}{lllll}
\hline Groups & CS Preexposure & Conditioning & CS Extinction & Test \\
\hline Same & $96 \mathrm{Y}-(\mathrm{C})$ & $4 \mathrm{X}+(\mathrm{A})$ & $96 \mathrm{X}-(\mathrm{B})$ & $\mathrm{X}(\mathrm{B})$ \\
& & $4 \mathrm{Y}+(\mathrm{A})$ & & $\mathrm{Y}(\mathrm{C})$ \\
Different & $96 \mathrm{Y}-(\mathrm{C})$ & $4 \mathrm{X}+(\mathrm{A})$ & $96 \mathrm{X}-(\mathrm{B})$ & $\mathrm{X}(\mathrm{C})$ \\
& & $4 \mathrm{Y}+(\mathrm{A})$ & & $\mathrm{Y}(\mathrm{B})$ \\
& & & &
\end{tabular}

"Same" and "Different" refer to whether testing occurred in the context of nonreinforcement treatment (Same) or in a different context, both of which were dissimilar to the context of conditioning. $\mathrm{X}$ and $\mathrm{Y}$ were a click train and a tone, counterbalanced. "+" denotes reinforcement with a mild footshock; "-" denotes no reinforcement. Letters in parentheses indicate contexts, and Contexts B and C were counterbalanced. Numbers preceding the letters indicate the total number of trials in that phase

stimulus control in the neutral context should reflect release from the context specificity of nonreinforcement due to nonreinforcement being context specific, plus release from any context specificity of the nonreinforcement treatment due to nonreinforcement being learned second. In contrast, in the latent inhibition condition, the increased stimulus control in the neutral context should reflect release from the context specificity of nonreinforcement due to nonreinforcement being context specific, minus any context specificity of the excitatory conditioning due to excitatory conditioning being learned second. Thus, the context specificity of what was learned second would take the form of an interaction between the cue (X vs. Y) and the test context (Same vs. Different).

\section{Method}

\section{Subjects}

The subjects were 24 male (183-325 g) and 24 female (161219 g), experimentally naive, Sprague-Dawley descended rats obtained from our own breeding colony. Subjects were randomly assigned to one of two groups (Same and Different, $n \mathrm{~s}=24$ ), counterbalanced within groups for sex. The housing and maintenance of all subjects were identical to those aspects of Experiment 1.

\section{Apparatus}

As in Experiment 1, a 30-s click train and a 30-s complex tone served as CS X and CS Y (counterbalanced within groups), and a $0.7-\mathrm{mA}, 0.5$-s footshock served as the US. Six instances of Chamber R (which now contained Plexiglas floor on top of the steel rod floor) and six instances of Chamber $\mathrm{V}$ were used as Contexts $\mathrm{B}$ and $\mathrm{C}$, counterbalanced within groups. A third chamber, Chamber Modified-R (12 instances) was used as Context A for all subjects. This chamber was the same as Chamber R, with five modifications: (1) a different instance of Chamber R, (2) the Plexiglas floor covering was removed to reveal the stainless steel rods beneath, (3) the house light was off, (4) a daily drop of methyl salicylate was placed onto a small block of wood located inside the isolation chest, and (5) no lick tube was present in this context.

\section{Procedure}

Acclimation On Day 1, all subjects were acclimated to Contexts $\mathrm{B}$ and $\mathrm{C}$ for $30 \mathrm{~min}$ each with the order of sessions counterbalanced within groups. The procedural details were exactly as in Experiment 1.

CS preexposure On Days 2 and 3, all subjects received a daily 60-min session in Context $\mathrm{C}$ with no lick tube present. Subjects in both groups received 48 daily nonreinforced presentations of Y with a mean ITI of $1.25 \mathrm{~min}$, from CS onset to CS onset. The number of nonreinforced presentations was increased from 16 per day in Experiment 1 to 48 with the intent of avoiding a ceiling effect for conditioned suppression, which was relatively likely within a design in which the latent inhibition treatment is administered in a context different from that of excitatory conditioning. That is, latent inhibition effects are smaller when the latent inhibition treatment is administered outside the conditioning context (Bouton \& Bolles, 1979; Channell \& Hall, 1981; Hall \& Minor, 1984). The present increase in the number of nonreinforced exposures to the target CSs was intended to compensate for this.

CS conditioning On Days 4 and 5, all subjects received two daily 60-min sessions, one consisting of two presentations of $\mathrm{X}$ coterminating with the US in Context A with 30-min ITIs (from CS onset to CS onset), and the other consisting of two presentations of $\mathrm{Y}$ coterminating with the US in Context A with the same ITI. Procedural details were identical to those in Experiment 1.

CS extinction On Days 6 and 7, all subjects received a daily 60-min session in Context B with no lick tube present. The subjects in both groups received 48 daily nonreinforced presentations of X with a mean ITI of $1.25 \mathrm{~min}$, from CS onset to CS onset.

Reacclimation On Days 8 and 9, all subjects were reacclimated to Contexts $\mathrm{B}$ and $\mathrm{C}$ for 30-min each with the order of sessions counterbalanced within groups. The time between sessions was approximately $200 \mathrm{~min}$. In these sessions, the subjects had free access to water-filled lick tubes and no nominal stimulus was programmed to occur. The purpose of these sessions was to reestablish stable drinking behavior (which might have been differentially disrupted by prior training), thereby producing similar baseline behavior 
across the two groups in both Contexts B and C, upon which conditioned lick suppression could be assessed.

Testing All subjects were tested once daily on two consecutive days (Days 10 and 11). During the test sessions, the subjects had free access to water-filled tubes. All subjects were tested for conditioned lick suppression to $\mathrm{X}$ and $\mathrm{Y}$ on separate days, with the order of testing being counterbalanced within groups. The subjects in Group Same were tested in the contexts in which each $\mathrm{CS}$ had been nonreinforced (i.e., $\mathrm{X}$ in Context $\mathrm{B}$ and $\mathrm{Y}$ in Context $\mathrm{C}$ ), whereas the subjects in Group Different were tested in contexts different than those in which each $\mathrm{CS}$ had been nonreinforced (i.e., $\mathrm{X}$ in Context $\mathrm{C}$ and $\mathrm{Y}$ in Context B). Except for the contexts of testing, all procedures, data recording, and transformations were done as in Experiment 1 . No subjects were excluded from the present experiment on the basis of the elimination criterion.

\section{Results}

The results of Experiment 2 are depicted in Fig. 2. When subjects were tested outside the context of nonreinforced treatment for the target cue (i.e., Group Different), they exhibited strong conditioned suppression to the cues that were extinguished $(\mathrm{X})$ and preexposed $(\mathrm{Y})$, as compared with suppression by the subjects tested in the contexts in which they had received nonreinforced treatment with that target cue (i.e., Group Same). More specifically, testing an extinguished cue in a neutral but familiar context produced more conditioned suppression than did testing the same cue in the context in which the extinction treatment had taken place (i.e., $\mathrm{ABC}$ renewal). Likewise, testing a preexposed cue in a neutral but familiar context produced more conditioned suppression than did testing the same cue in the context in which preexposure had occurred (i.e., release from latent inhibition). Additionally, the amounts of conditioned suppression to X and Y were similar in Group Same and were also similar in Group Different. The following statistical analysis supported these conclusions.

A 2 (Context of Testing: Same vs. Different) $\times 2$ (Cue: X vs. Y) $\times 2$ (Order of Tests: $\mathrm{X}$ first vs. Y first) ANOVA applied to the log pre-CS latencies (i.e., the time to complete the first 5 cumulative seconds of drinking in the absence of the CS) on the test days detected no significant main effect or interaction (smallest $p=.10$ ), indicating that the experimental conditions did not differ appreciably in baseline drinking. The pre-CS means were $1.23 \log \mathrm{s}($ Group Same X), $1.19 \log \mathrm{s}$ (Group Same Y), $1.22 \log \mathrm{s}$ (Group Different X), and $1.17 \log \mathrm{s}$ (Group Different Y). A parallel analysis of the latencies to complete 5 cumulative seconds of drinking in the presence of the CS detected a main effect of the context of testing, $F(1,88)=17.26, p<.01, M S E=0.12, \eta_{\mathrm{p}}{ }^{2}=.16(95 \% \mathrm{CIs}$

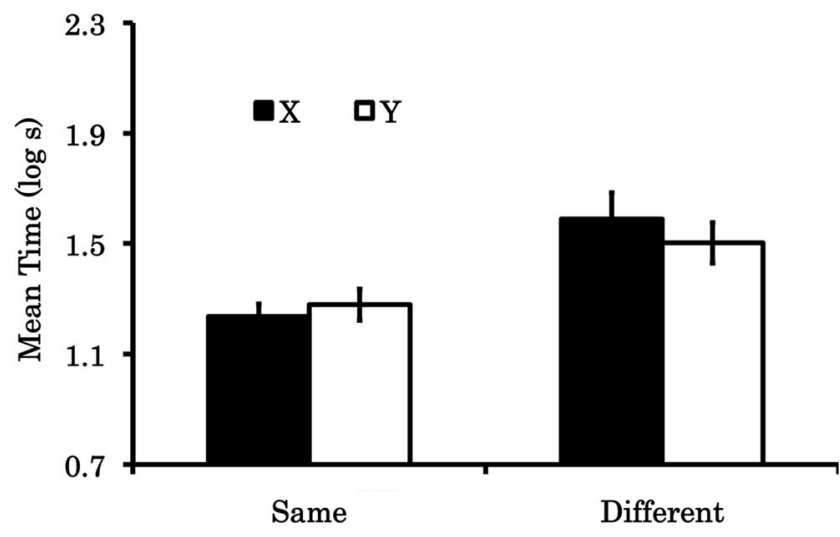

Fig. 2 Results of Experiment 2: Mean $\log _{10}$ times to complete 5 cumulative seconds of licking in the presence of the target CSs $\mathrm{X}$ and $\mathrm{Y} . \mathrm{X}=$ target cue that received extinction treatment; $\mathrm{Y}=$ target cue that received CS-preexposure treatment; Same $=$ group that was tested for responding to $\mathrm{X}$ and $\mathrm{Y}$ in the context in which each of the cues was nonreinforced (i.e., $\mathrm{X}$ in Context $\mathrm{B}$ and $\mathrm{Y}$ in Context C); Different = group that was tested for responding to $\mathrm{X}$ and $\mathrm{Y}$ outside the context in which each of the cues was nonreinforced (i.e., $\mathrm{X}$ in Context $\mathrm{C}$ and $\mathrm{Y}$ in Context B). Brackets represent the standard errors of the means. Higher scores indicate more conditioned fear, and $0.7 \log \mathrm{s}$ was the lowest possible score. See the text and Table 2 for further details

$=.05, .30)$, indicating that overall, when subjects were tested in a context different from that in which the nonreinforced treatment had occurred, they displayed greater conditioned suppression. That is, Group Different exhibited more conditioned suppression than Group Same. All other main effects and interactions were nonsignificant (smallest $p=.13$ ).

Planned comparisons were performed to evaluate the differences between responding to $\mathrm{X}$ and $\mathrm{Y}$ within each test context group (i.e., Same and Different). A nonsignificant difference in responding to $\mathrm{X}$ and $\mathrm{Y}$ in Group Same, $F(1$, $88)=0.19, p=.66$, and a nonsignificant difference in responding to the same cues in Group Different, $F(1,88)=$ $0.79, p=.38$, suggested that responding to the two cues was approximately equivalent in each of the groups. The near equality of the means between responding to $\mathrm{X}$ and $\mathrm{Y}$ in Group Same and between responding to $\mathrm{X}$ and $\mathrm{Y}$ in Group Different was confirmed by Bayesian analyses (Rouder et al., 2009), with odds of 32.29 in favor of the null hypothesis for the comparison in Group Same, and odds of 16.34 in favor of the null hypothesis for the comparison in Group Different.

Notably, in Experiment 2 the critical comparison was between the context specificity of the effects of extinction (i.e., $\mathrm{ABC}$ vs. $\mathrm{ABB}$ ) and the context specificity of the effects of latent inhibition treatment (i.e., $\mathrm{CAB}$ vs. $\mathrm{CAC}$ ). Thus, the control condition for extinction was tested in the same context as the Phase 2 (nonreinforcement) treatment (i.e., ABB), whereas the control condition for latent inhibition was tested in the same context as the Phase 1 (also nonreinforcement) treatment (i.e., CAC). Thus, one might expect the extinction treatment, by virtue of its superior recency with respect to test, to have a greater impact on test performance than would the 
latent inhibition treatment. However, in practice, three days passed between the end of Phase 2 treatment and test, during which reacclimation occurred with multiple exposures to both Contexts B and C. This presumably minimized any effect of the differential recencies of nonreinforcement relative to test between the extinction and latent inhibition conditions.

These findings, in conjunction with the absence of any interaction between responding to $\mathrm{X}$ and $\mathrm{Y}$, indicate a parallel between extinction and latent inhibition effects: Both are subject to reduced impact of nonreinforced trials when testing occurs outside the context of nonreinforcement. Thus, at least with the present parameters, the magnitude of the ABC renewal effect for extinction appears to be similar to the analogous release from the latent inhibition effect. This suggests that in this situation, at least with the present parameters, nonreinforcement being learned second (i.e., extinction) relative to its being learned first (latent inhibition treatment) does not appreciably influence the context specificity of learning about the nonreinforcement. Thus, Experiment 2 conceptually replicated the central finding of Experiment 1, now in a situation in which conditioning and nonreinforcement occurred in different contexts.

\section{General discussion}

\section{Implications for Bouton's (1993) two hypotheses}

As previously noted, our designs allowed us to directly compare in a single experiment conditioned suppression elicited by an extinguished cue and by a preexposed cue in the context in which each cue had been nonreinforced and outside that context. This feature permitted us to assess Bouton's (1993) two hypotheses concerning what information becomes context specific after a cue has become ambiguous by being sequentially reinforced and nonreinforced. One hypothesis is that what becomes context dependent after a cue is both reinforced and nonreinforced is the memory of nonreinforcement. In this framework, excitatory learning is thought to be less susceptible to contextual changes than is the inhibitory-like learning that may occur during nonreinforced trials. Bouton's second hypothesis, not necessarily exclusive with respect to the suggestion that information concerning nonreinforcement is context specific, is that second-learned information becomes context specific. Evidence indirectly supporting this account comes from studies in which the target cue received both excitatory conditioning and Pavlovian conditioned inhibition training (as opposed to excitatory conditioning and nonreinforced presentations of the CS as in the present research). For example, Nelson (2002) found that independent of the order of training, if a cue is sequentially trained as a conditioned excitor and as a conditioned inhibitor, information acquired second was context dependent. Sissons and Miller (2009) found that the same was true when the temporal contexts were manipulated instead of the physical context of training; that is, information learned first showed "spontaneous" recovery independent of its being excitatory or inhibitory. The present experiments examined whether this second hypothesis (i.e., second-learned information concerning a cue is context dependent), which seemingly applies when the two phases of treatment consist of excitatory conditioning and Pavlovian inhibitory conditioning, also applies when the two phases of treatment consist of excitatory conditioning and simple nonreinforced presentations of the target CS as are administered in extinction and latent inhibition treatments.

These two potential mechanisms should have summative effects on responding to an extinguished CS (because in an extinction paradigm the second-learned information about the CS concerns nonreinforcement). But they should have opposing effects on responding to a preexposed CS (because in a latent inhibition paradigm the second-learned information about the CS concerns excitatory conditioning). Hence, a difference between the context specificities of extinction and latent inhibition treatments is potentially a measure of the extent to which second-learned information is context specific at least in this situation (i.e., phasic excitatory conditioning and nonreinforcement) with the present matched parameters. The observed absence of any appreciable difference between CS X and CS Y in terms of context specificity of conditioned suppression suggests that the process that makes second-learned information context specific was inoperative here. In contrast, the observed equivalent context specificity of extinction and latent inhibition treatments testifies that the process that makes information concerning nonreinforcement context specific was operative in the present situation. Critically, these conclusions depended on our use of operationally matched procedures and parameters for extinction and latent inhibition treatments.

Experiments 1 and 2 each conceptually replicate numerous prior reports of reduced attenuation of stimulus control by extinction and latent inhibition treatments when testing occurs outside of the context of nonreinforcement. This was seen regardless of whether excitatory conditioning occurred in the same context as nonreinforcement (Exp. 1) or in a different context (Exp. 2). These experiments not only conceptually replicated prior research; the present results were obtained with extinction and latent inhibition treatments being administered within the same experiment and with matched operational parameters. Clearly, and unsurprisingly, the behavioral consequences of nonreinforced exposure to the target CSs transferred relatively weakly to a context different than that in which nonreinforced exposure to the CSs had occurred. Of greater interest, the absence of an appreciable interaction 
between cues (i.e., $\mathrm{X}$ vs. Y) and test context (i.e., Same vs. Different) in each experiment suggests that, in the present situation, transfer of second-learned nonreinforcement (i.e., extinction) was no different than transfer of first-learned nonreinforcement (i.e., latent inhibition treatment). Moreover, although one might expect knowledge of excitatory conditioning in the latent inhibition condition to be more context specific (than in the extinction condition) because excitatory conditioning was learned second, no suggestion of such an effect was observed. Thus, at least with the present design (i.e., nonreinforcement and excitatory aversive conditioning) and parameters, information concerning nonreinforcement of a CS did not to any large degree depend on whether nonreinforcement was the first or second thing learned about the CS. The present absence of any appreciable interaction suggests that neither secondlearned nonreinforcement nor second-learned conditioning is context specific relative to their being first learned in latent inhibition and extinction situations. Alternatively stated, our results suggest that nonreinforcement alone determines which context will play the modulatory (i.e., occasion setting) role in situations like this.

Of course it is possible that a difference between the extinguished cue $(\mathrm{X})$ and preexposed cue $(\mathrm{Y})$ in what was learned during the nonreinforced treatment (due to whether or not conditioning preceded nonreinforcement) compensated for any greater context specificity of knowledge of nonreinforcement concerning the extinguished cue than the preexposed cue. But such a two-process account would leave unspecified the nature of this difference in learning concerning nonreinforcement and it is far less parsimonious than the view that the nature of what was second learned (i.e., nonreinforcement vs. conditioning) is irrelevant to the context specificity of knowledge concerning nonreinforcement. Hence, although this two-process account cannot be categorically rejected, it appears to be relatively implausible. When two phenomena have the same properties, the most parsimonious (although not certain) conclusion is that they arise from common underlying processes. In the present case we seemingly see extinction and latent inhibition treatments as two examples of two-phase associative interference involving excitatory conditioning in one phase and simple nonreinforced presentations of the target cue in the other phase.

\section{Implications beyond Bouton's (1993) accounts}

Although we observed that the effects of extinction and latent inhibition treatments are relatively specific to the context of nonreinforcement, and we use these findings to suggest that the effects of extinction and latent inhibition treatments may be a product of a single interference mechanism, we acknowledge the remaining possibility that the context specificity of nonreinforcement evidenced here in extinction and latent inhibition effects might well have arisen from different mechanisms. During an extinction treatment, organisms experience a violation of an established US expectation, which may encourage the context to acquire modulatory properties (e.g., Bouton, 1993) or direct inhibitory properties (e.g., Polack, Laborda, \& Miller, 2012) that support less stimulus control of behavior in the context of extinction treatment than in a neutral context. In the case of a latent inhibition treatment, there is no violation of US expectations during CS-alone presentations, since the CS has not yet been reinforced. Thus, some form of conditioned inhibition is possibly at play in producing experimental extinction that could not contribute to latent inhibition effects. Thus, despite our observing a parallel in the nature of context specificity between extinction and latent inhibition effects in the present experiments, these effects still may not share a common underlying mechanism. The present observations add to the already existing evidence supportive of a common interference mechanism, but surely additional research on this issue is needed.

\section{Inconsistency with prior research}

In summary, Experiments 1 and 2 provided convergent results suggesting that the memory of nonreinforcement per se becomes equally context dependent after a cue is both reinforced and nonreinforced regardless of whether nonreinforcement precedes or follows excitatory conditioning. We make no assertion about the context specificity of conditioned excitation because the present experiments were not designed to examine that issue. We only contrasted the context specificity of memory of nonreinforcement treatment before excitatory conditioning with the context specificity of memory of nonreinforcement treatment after excitatory conditioning. Our conclusion is contrary to some prior reports, most notably that of Lovibond et al. (1984, Exp. 2), who also examined the context specificity of extinction and latent inhibition effects within a single experiment. However, Lovibond et al. did not use the same parameters for their extinction and latent inhibition treatments. As previously noted, our conclusion that extinction and latent inhibition effects are equally sensitive to whether testing occurs inside or outside the context used for nonreinforcement contrasts with the observed context specificity of what gets learned second when phasic excitatory conditioning and Pavlovian inhibitory conditioning are administered in Phases 1 and 2. This difference highlights the distinction between nonreinforcement in conditioned inhibition training (in which a specific US is expected at the time of nonreinforcement) and nonreinforcement during CS-preexposure treatment (in which there is no expectation of a US at the time of nonreinforcement). 


\section{Contrasting the context specificity of extinction learning with that of conditioned inhibition training}

In the present experiments, the context specificity of extinction effects seems to be driven by the same mechanism as the one that produces the context specificity of latent inhibition treatment (i.e., knowledge of nonreinforcement is context specific), or at least by an analogous mechanism. This is somewhat surprising, because in recent years extinction learning (but not learning during latent inhibition treatment) has often been viewed as a form of inhibition learning because nonreinforcement during extinction treatment occurs when there is an expectation of the specific US that has already been presented during excitatory conditioning (e.g., Bouton, 1993). However, one must note the clear operational difference between Pavlovian conditioned inhibition training, in which the expectation of the US arises from a conditioned excitor that is compounded with the inhibitory CS, and the extinction treatment, in which the prevailing view is that the expectation of the US arises from the cue itself that is being extinguished. Whether and why this operational difference alters the mechanism responsible for the context specificity of information concerning nonreinforcement is a question that future research will have to address. Moreover, the present research was not designed to examine why memories of nonreinforcement per se (as opposed to conditioned inhibition training) are more context specific than memories of excitatory conditioning. That, too, is a question that calls for future examination.

In contrast to the memory of target cue nonreinforcement established during cue-alone presentations, which is similarly context dependent whether the memory is formed before or after excitatory conditioning, memories of target cue nonreinforcement that are established during Pavlovian conditioned inhibition training have been reported to be far more context dependent when the inhibitory training is learned second (i.e., when it follows as opposed to precedes the excitatory conditioning; Nelson, 2002; Sissons \& Miller, 2009). Hence, the present conclusions concerning cue nonreinforcement within latent inhibition and extinction procedures should not be overgeneralized to cue nonreinforcement experienced within Pavlovian conditioned inhibition training.

\section{Other accounts of the present data}

Thus far, our analysis of the context specificity of stimulus control following phasic reinforcement and nonreinforcement has focused on Bouton's (1993) two accounts, because they are the ones that are most widely cited. Notably, in both of Bouton's accounts, the test context serves as an occasion setter for CS-US association being tested. However, other, very different mechanisms might contribute to the observed context specificity of nonreinforced exposures to a CS. For example, Wagner's (1981) SOP model suggests that many nonreinforced presentations of a CS in a given context establish a strong context-CS association. At test in the context of nonreinforcement, prior to CS onset the test context presumably activates a representation of the CS into Wagner's A2 state, which leaves the representation of the CS unavailable to be activated into Wagner's A1 memory state when the CS is actually presented. According to SOP, this would reduce the potential of the CS at test to activate a representation of the US, and hence to elicit a conditioned response. When applied to $\mathrm{AAB}$ renewal (e.g., Exp. 1) and $\mathrm{ABC}$ renewal (e.g., Exp. 2), this account is parameter independent. Thus, SOP can fully explain our observations in both of the present experiments, by positing a role for a CS-context association instead of a contextually occasion-set memory of CS nonreinforcement as was proposed by Bouton (1993). However, SOP fails to account for the previously cited data demonstrating that when the two phases of training consist of excitatory and inhibitory conditioning of the same cue, only the information that is acquired second is context specific.

\section{Conclusions}

In summary, the present research does not prove that the context specificity of nonreinforcement experience is due to occasion setting by the context of nonreinforcement, because there are alternative accounts of our data, such as the one provided by Wagner's (1981) SOP model. But our research does refute the view that this context specificity is due to occasion setting of retrieval of the memory of CS-alone trials by the context in which the CS-alone trials occurred, which arises because the CS-alone trials were the information that was learned second concerning the CS.

Additionally, independent of the specific mechanism by with behavior consistent with nonreinforcement of a CS becomes specific to the context in which nonreinforcement of the CS was experienced, an important new conclusion can be drawn from the present data. That is, much, if not all, of the response deficits produced by extinction and latent inhibition treatments are due to performance deficits rather than to an absence of knowledge concerning excitatory conditioning (i.e., a lack of learning, in the case of a latent inhibition treatment, or irrevocable erasure of the memory of conditioning, in the case of extinction). This is a widely recognized aspect of extinction (e.g., Bouton, 1993 - total error reduction models of learning, such as that of Rescorla \& Wagner, 1972, notwithstanding), but it is less recognized for the response deficit produced by a latent inhibition treatment. Latent inhibition effects are still often regarded as the consequences of an attention deficit that irrevocably disrupts subsequent excitatory acquisition (e.g., Lubow, 1989). Considerable evidence now indicates that nonreinforced presentations of a CS after CSUS pairings do not erase the previously acquired excitatory 
associations, in the case of extinction, nor prevent excitatory acquisition, in the case of latent inhibition. Instead, during nonreinforced trials a new association (i.e., CS-no US) is formed that competes for behavioral control with the original CS-US association (e.g., Bouton, 1993). Whether the CS-US or the CS-no US association is behaviorally expressed at test depends both on the strength of each association and on what facilitatory cues for each association are present at test (Laborda \& Miller, 2012; Miller \& Laborda, 2011). Of course, the test context, which we have examined here, is a potentially facilitatory cue present at test (Bouton, 1993).

Author Note National Institute of Mental Health Grant Number 33881 supported this research. M.A.L. and G.M. were supported by the Chilean Fondo Nacional de Investigación Científica y Tecnológica, Grant Number 1130117, and the Chilean Programa de Atracción e Inserción de Capital Humano Avanzado, Grant Number 79140028. G.M. was also supported by the US-Chilean Fulbright program. The authors thank Fannie Chen, Tiffany Kurian, Sarah O'Hara, Juan M. Rosas, Julia Soares, Steven Still, Chris Szabo, Jessica Wasserman, and Deanne Westerman for their comments on an earlier version of the manuscript.

\section{References}

Bouton, M. E. (1993). Context, time, and memory retrieval in the interference paradigm of Pavlovian learning. Psychological Bulletin, 114, 80-99. doi:10.1037/0033-2909.114.1.80

Bouton, M. E., \& Bolles, R. C. (1979). Contextual control of the extinction of conditioned fear. Learning and Motivation, 10, 445-466. doi: 10.1016/0023-9690(79)90057-2

Bouton, M. E., \& King, D. A. (1983). Contextual control of the extinction of conditioned fear: Tests for the associative value of the context. Journal of Experimental Psychology: Animal Behavior Processes, 9, 248-265. doi:10.1037/0097-7403.9.3.248

Channell, S., \& Hall, G. (1981). Facilitation and retardation of discrimination learning after exposure to the stimuli. Journal of Experimental Psychology: Animal Behavior Processes, 7, 437446. doi:10.1037/0097-7403.7.4.437

Escobar, M., Arcediano, F., \& Miller, R. R. (2002). Latent inhibition and contextual associations. Journal of Experimental Psychology: Animal Behavior Processes, 28, 123-136. doi:10.1037/0097-7403. 28.2.123

Hall, G., \& Minor, H. (1984). A search for context-stimulus associations in latent inhibition. Quarterly Journal of Experimental Psychology, $368,145-169$.

Harris, J. A., Jones, M. L., Bailey, G. K., \& Westbrook, R. F. (2000). Contextual control over conditioned responding in an extinction paradigm. Journal of Experimental Psychology: Animal Behavior Processes, 26, 174-185. doi:10.1037/0097-7403.26.2.174

Laborda, M. A., \& Miller, R. R. (2012). Reactivated memories compete for expression after Pavlovian extinction. Behavioural Processes, 90, 20-27.
Laborda, M. A., Witnauer, J. E., \& Miller, R. R. (2011). Contrasting AAC and $\mathrm{ABC}$ renewal: The role of contexts associations. Learning \& Behavior, 39, 46-56. doi:10.3758/s13420-010-0007-1

Lovibond, P. F., Preston, G. C., \& Mackintosh, N. J. (1984). Context specificity of conditioning, extinction, and latent inhibition. Journal of Experimental Psychology: Animal Behavior Processes, 10, 360-375. doi:10.1037/0097-7403.10.3.360

Lubow, R. E. (1989). Latent inhibition and conditioned attention theory. Cambridge: Cambridge University Press.

Lubow, R. E., \& Moore, A. U. (1959). Latent inhibition: The effect of nonreinforced preexposure to the conditioned stimulus. Journal of Comparative and Physiological Psychology, 52, 415-419. doi:10. 1037/h0046700

Maes, J. H. R. (2002). No sex difference in contextual control over the expression of latent inhibition and extinction in Pavlovian fear conditioning in rats. Neurobiology of Learning and Memory, 78, 258278.

Miller, R. R., \& Laborda, M. A. (2011). Preventing recovery from extinction and relapse: A product of current retrieval cues and memory strengths. Current Directions in Psychological Science, 20, 325329. doi: $10.1177 / 0963721411418466$

Nelson, J. B. (2002). Context specificity of excitation and inhibition in ambiguous stimuli. Learning and Motivation, 33, 284-310.

Nelson, J. B. (2009). Contextual control of first- and second-learned excitation and inhibition in equally ambiguous stimuli. Learning \& Behavior, 37, 95-106. doi:10.3758/LB.37.1.95

Pavlov, I. P. (1927). Conditioned reflexes. In G. V. Anrep (Ed. \& Trans.), London, UK: Oxford University Press.

Polack, C. W., Laborda, M. A., \& Miller, R. R. (2012). Extinction context as a conditioned inhibitor. Learning \& Behavior, 40, 24-33. doi:10. 3758/s13420-011-0039-1

Rescorla, R. A. (2008). Within-subject renewal in sign tracking. Quarterly Journal of Experimental Psychology, 61, 1793-1802. doi:10.1080/17470210701790099

Rescorla, R. A., \& Wagner, A. R. (1972). A theory of Pavlovian conditioning: Variations in the effectiveness of reinforcement and nonreinforcement. In A. H. Black \& W. F. Prokasy (Eds.), Classical conditioning: II. Current theory and research (pp. 6499). New York: Appleton-Century Crofts.

Rouder, J. N., Speckman, P. L., Sun, D., Morey, R. D., \& Iverson, G. (2009). Bayesian $t$ test for accepting and rejecting the null hypothesis. Psychonomic Bulletin \& Review, 16, 225-237. doi:10.3758/ PBR.16.2.225

Sissons, H. T., \& Miller, R. R. (2009). Spontaneous recovery of excitation and inhibition. Journal of Experimental Psychology: Animal Behavior Processes, 35, 419-426.

Wagner, A. R. (1981). SOP: A model of automatic processing in animal behavior. In N. E. Spear \& R. R. Miller (Eds.), Information processing in animals: Memory mechanisms (pp. 5-47). Hillsdale: Erlbaum

Westbrook, R. F., Jones, M. L., Bailey, G. K., \& Harris, J. A. (2000). Contextual control over conditioned responding in a latent inhibition paradigm. Journal of Experimental Psychology: Animal Behavior Processes, 26, 157-173. doi:10.1037/0097-7403.26.2.157

Wheeler, D. S., Chang, R. C., \& Miller, R. R. (2003). Massive preexposure and preexposure in multiple contexts attenuate the context specific of latent inhibition. Learning \& Behavior, 31, 378-386. 